\title{
La Escritura, \\ la Ilustración europea y el mito del Buen Salvaje. El caso de: La sociedad de Amantes del País, Lima (1791-1795)
}

Jeremy Dioses Campaña

\begin{abstract}
Miembro del laboratorio CNPQ Patrimônio e Relações Internacionais y del Laboratório de Patrimônios Culturais (LAPA) vinculados al ICH de la UFJF doi: 10.46476/ra.v2i1.96
\end{abstract}

\section{Resumen}

En este trabajo ${ }^{1}$ se ha estudiado el arquetipo del Buen Salvaje, presente en los artículos publicados en el Mercurio Peruano, entre 1791 y 1795 . Este fue adaptado y utilizado por los miembros de este periódico para mantener el orden social y conservar sus privilegios, haciendo uso de la ilustración - estructura de pensamiento colonial eurocéntrica- que se alzó como racional y antagónica a la matriz de pensamiento andino y africano, entendidas como míticas e inferiores. Sin embargo, lo racional como argumento para posicionarse hegemónicamente sobre las otras estructuras de pensamiento, es insuficiente porque el pensamiento eurocéntrico presenta una serie de elementos míticos, reproducidos por los principales filósofos europeos que influenciaron a la Sociedad de Amantes del País. Y, a pesar de las contradicciones, esta estructura de pensamiento se mantuvo y sobre ella se fundó la República del Perú, evidenciando su naturaleza en la exclusión de los grupos indígenas y los grupos de origen africano de los proyectos nacionales.

\section{Introducción}

La Sociedad de Amantes del País y su órgano difusor El Mercurio Peruano son entendidos, en nuestro trabajo, como elementos de una maquinaria compleja

1. Tesis para optar el grado de magister, defendida el 2020 en la Universidad Federal Juiz de Fora (UFJF-Brasil). 
y con contradicciones que forman parte de un cuerpo mayor de intelectuales y sociedades de conocimiento, vinculados, epistemológicamente, a una estructura de pensamiento eurocéntrico y colonialista. Este se encuentra en una constante construcción, a partir dela influencia de los principales intelectuales dela Ilustración europea, sobre aquellos que estaban emergiendo en estos espacios colonizados. Las citas en los artículos del Mercurio Peruano, acusan la presencia de Buffon, De Paw, Jorge Juan y Antonio Ulloa, Rousseau, Voltaire, entre otros. Todos ellos vinculados por sostener el mito de la superioridad europea sobre los otros grupos humanos que no pertenecían a ese continente y que eran entendidos como salvajes. Así, el mito constituyó un mecanismo para afirmar la existencia de algo que no puede ser comprobado, tal cual lo hacen algunas sociedades para explicar «[...] el origen de las cosas que existen mediante historias de dioses. A este modo de interpretar el origen de las cosas se llama mito» (Arguedas, 2001, p. 8). Los depositarios y constructores de este pensamiento se encargaron de instrumentalizar el mito para mantener el culto al hombre europeo y pensarlo como el portador de la razón que antagoniza al «salvaje» indígena y africano. Y, este antagonismo conceptual fue la columna vertebral sobre la cual se articularon otros conceptos que sustentaron el colonialismo.

De este corpus conceptual, dirigido a la dominación de los indígenas y africanos, se evidencia una mayor influencia de Voltaire en las producciones del Mercurio Peruano.

[...] En América española, Rousseau fue vencido, pero no Voltaire. Nosotros favorecimos, en su historia la promesa de Voltaire - el devenir debía ser racional, feliz y orientado por una minoría iluminada (Fuentes, 1981, p. 21, traducción nuestra).

En efecto, la Sociedad de Amantes del País se organizó fiel al formato de Voltaire, concibiéndose a sí misma como un grupo minoritario con la función de llevar las luces al resto de la población, considerada incapaz de servirse de su propia inteligencia. Por esta razón, Kant menciona que «La Ilustración es la liberación del hombre de su culpable incapacidad. La incapacidad significa la imposibilidad de servirse de su inteligencia sin la guía de otro» (2013, p. 25). Así, la consecuencia de asumir este concepto de ilustración y esta forma de organización fue la marginación de las mayorías de estos espacios de reflexión y la construcción de discursos, fórmulas lingüísticas, sobre lo que significa ser un negro (africano), un indígena y un blanco en estos espacios colonizados. Estos discursos se desarrollaron a partir de conceptos ya existentes desde Colón, que reinterpretaron, haciendo uso de los aportes de los ilustrados, con principal atención en las producciones de Voltaire. Los conceptos, con base mítica, tomados de este pensamiento fueron: el tiempo lineal, el salvajismo de los subalternizados y el determinismo en todo lo existente 
(como el mito de la superioridad europea sobre los africanos e indígenas, y otros mitos de la Ilustración.) «[...] Los árboles de pera nunca pueden dar piñas. [...] Está todo determinado, interdependiente, limitado» (Arouet, 1978, pp. 148149, traducción nuestra), a partir del cual justifica la existencia de esclavos y del ordenamiento en la estructura social. Asimismo, Voltaire, antes de morir - en una carta del dos de marzo de 1778 - confirma que su pensamiento mítico se hallaba tan presente en él como su pensamiento racional, entendido como antagónico al pensamiento mítico, al ofrecerle disculpas al dios judeocristiano. Pues, a pesar de que se alzara como un pensador depositario de la razón, estaba pidiéndole perdón a algo o alguien que no tiene una existencia comprobada, tal cual lo harían los incas, mayas o aztecas con sus propias deidades. Este tipo de contradicciones también las vamos a percibir en las producciones de los miembros del Mercurio Peruano.

En los artículos del Mercurio Peruano, la idea del tiempo lineal operó junto con la creencia de un pasado único a toda la humanidad, ordenado por el dios judeocristiano (idea adaptada del siglo XVI) y dirigido a un único destino (el retorno al origen o paraíso). En este sentido, Pedro Nolasco Crespo trata de explicar racionalmente problemas vinculados a la naturaleza humana a partir de una concepción mítica, propia de la tradición cristiana. «Por la verdad, sin negar el que por el Diluvio Universal haya sido algún tanto maltratada nuestra naturaleza, y alterádose de aquel bello plan con que el que por la sacó de sí el Eterno poder del Soberano Artífice» (1964: II, p. 279). Esto provocó una contradicción dentro de sus propios lineamientos epistemológicos y además colocó a los grupos indígenas y de origen africano en una única lectura de tiempo histórico lineal y progresiva que se ajusta a un plan divino de retorno al origen o paraíso. Con el objetivo de desplazar las lecturas de tiempo histórico circulares, propias de la matriz de pensamiento de estos pueblos, y colocarlos - en el discurso- en un estado de salvajismo, anterior al hombre europeo que se posiciona a sí mismo en la vanguardia de esta línea evolutiva, trazada por el pensamiento occidental, según Unanue «Los Agoreros Peruanos consultan sus Divinidades destrensandose el pelo que lo traen muy largo, cubren con parte de él la cara, beben chicha, mascan coca, se introducen en cabernas subterráneas y obscuras, y en medio de un silencio espantoso entonan cantos fúnebres» (1964: XI, p.207).

Asimismo, las prácticas religiosas de los grupos de origen africano también fueron entendidas como prácticas de salvajes, que son imposibles de abandonar y, en consecuencia, salir de ese estadio considerado inferior, según José Rosi y Rubí «[...] El aparato fúnebre de esta función es un testimonio irrefragable, de que el Bozal no muta de corazón como de país; pues mantiene [...] su superstición y su idolatría» (1964: II, p. 123).

Asimismo, su moral y sus expresiones culturales también fueron catalogados como salvajes por José Rossi y Rubí en el artículo Apólogo histórico sobre la corrupción 
de las colonias romanas de África, pues argumenta que la lascivia era inherente a su naturaleza, así como la deformidad, la monstruosidad, la longevidad, el gigantismo, publicados en otros artículos sobre medicina. De esta forma, dejaba en evidencia la reproducción de los argumentos usados por Colón, pero desde una matriz de pensamiento ilustrado, como lo demuestra Baquíjano. "En dias pasados una Negra Bozal llamada Mariana, Esclava de cierta Señora principal de esta Ciudad, parió un monstruo digno de la consideración de los Físicos, y admiración de los curiosos» (1964: I, p. 7).

Por todo lo mencionado, el Buen Salvaje es un sujeto subalternizado en todas sus áreas. Pero, ¿qué es un sujeto subalternizado? Un sujeto es un ingrediente activo, capaz de pensar su realidad y actuar en la estructura social (Akassi, inédito). Pero, que en su estado de subalternización los miembros del Mercurio Peruano le han atribuido características que lo degradan para justificar su dominación, como el salvajismo inherente a su naturaleza, la deformidad, el pensamiento mítico (irracional) y la indecencia relativa a su color de piel (en el caso de los africanos). Esto último nos indica que hay gradualidades en todo el espectro de este concepto, en donde los de origen africano son los menos favorecidos. Y, haciendo uso de estas características, los miembros de este periódico colocaron en desventaja al sujeto colonizado frente a ellos, negando sus aportes a la humanidad y volviéndolos susceptibles a ser apropiados e inseridos en una narrativa histórica occidental y colonialista, sostenida sobre una matriz de pensamiento ilustrado con contradicciones, que operó en función a los intereses de europeos y criollos.

\section{Problema y metodología}

Las mencionadas contradicciones detrás del mitode superioridad europea, presentes en La Sociedad de Amantes del País y su órgano difusor El Mercurio Peruano que exploramos en esta investigación, influyeron en el desarrollo del pensamiento de la élite criolla peruana, que construyó las bases del imaginario nacional, presente en el período republicano. Aunque la existencia del periódico se extendió solo por cuatro años, ellos vendrían a ser uno de los grupos más importantes en América Latina que dio continuidad a un proceso de poco más de cuatro siglos de presencia colonizadora en América, iniciada con la expedición de Colón en 1492, pasando por la invasión y colonización de 1532, que fue prolongada hasta 1824, año en el que fueron expulsados los españoles, pero no el colonialismo (AKASSI, inédito). Por esta razón, entendemos que el colonialismo es un proyecto político, pero también histórico en donde se coloca al hombre europeo y a su cultura como un paradigma a ser alcanzado en detrimento del sujeto subalternizado y de sus producciones culturales. Así, el colonialismo opera a través de los conceptos - revisados a lo largo del texto- articulados en discursos - fórmulas lingüísticas- que hacen efectivo el sometimiento experimentado por estos sujetos subalternizados. 
Con respecto a la metodología, debido a sus características, se utilizó el método lógico inductivo. Analizamos los conceptos que se encuentran en los escritos de Colón, pasando por otros europeos, como La Condamine, Jorge Juan y Santicilia y Antonio Ulloa, hasta llegar a los miembros del Mercurio Peruano. Para comprender este proceso, realizamos la recopilación de datos en fuentes documentales que involucran aspectos económicos, redes de sociabilización y documentación institucional perteneciente a organismos gubernamentales en los fondos del AGN. Asimismo, hicimos uso del método cualitativo porque tuvimos que concentrarnos en patrones presentes en los discursos que están conectados con la matriz de pensamiento eurocéntrico y colonialista.

\section{Discusión y Hallazgos}

La presente investigación parte de las lecturas de Fanon (1961), Mbembe (2016), Akassi (inédito), entre otros que, desde una posición poscolonial, escriben una historiografía que se aparta de la reproducción de conceptos eurocéntricos para pensar los fenómenos sociales acaecidos en sociedades colonizadas, mediante el uso de sus propias categorías. La otra estrategia para descolonizar el pensamiento es la resignificación de esos conceptos eurocéntricos (Akassi, inédito). Pero, para llegar a estos dos caminos, es necesario, inicialmente, deconstruir las estructuras de pensamiento eurocéntricas y visibilizar las contradicciones en el discurso colonialista.

Tomando en consideración estos planteamientos, nos concentramos en deconstruir los conceptos, poner en evidencia las contradicciones en los planteamientos de la ilustración que, claramente, era colonialista, y mostrar cómo los africanos e indígenas fueron sometidos y construidos conceptualmente desde esta matriz que los posicionó en la estructura para conservar los privilegios de la élite criolla, tal cual lo sugiere Baquíjano y Carrillo «[...] El trabajo de las Chacras, y el servicio domestico se ha hecho siempre por Negros. De quatro años á esta parte muchos Blancos se ocupan en uno y outro» (1964: I, p. 3).

Otro elemento a destacar en los hallazgos de la presente investigación es que existió una epistemología andina que fue invisibilizada o apropiada según fuera conveniente para los criollos y europeos. Según Lajo (2005), se diferencia de la cosmovisión eurocéntrica por la dualidad, pues, a través de este principio, se entiende la realidad a partir de la semejanza y no de un origen único que, como premisa inicial, degrada a todo lo diferente a él «[...] El concepto central de todos estos filósofos es la idea creadora o de origen en EL UNO» (2005, p. 121). Esto también fue cuestionado por Guamán Poma de Ayala en su libro Nueva Corónica y Buen Gobierno y por el Inca Garcilaso de la Vega en su libro Los Comentarios Reales de los Incas, publicado algunos siglos antes de la aparición del Mercurio Peruano, donde sutilmente cuestiona la dominación española y reconoce algunas 
buenas practicas comunitarias de los indígenas. No obstante, los miembros del Mercurio Peruano omitieron gran parte de estos testimonios del pensamiento andino y se apropiaron de lo que les era útil del Inca Garcilaso de la Vega para defenderse de sus detractores europeos, probando, a través de este escritor, que la geografía no los había degradado, pues él era un autor importante que había nacido en estos espacios. «[...] Garcilaso de la Vega en su Historia de los Incas excedió la curiosidad de los literatos de su siglo» (1965: V, p. 175).

En síntesis, la eficiencia del concepto del Buen Salvaje, reinterpretado por la Sociedad de Amantes del País, se encuentra en los argumentos que lo descalifican en las diferentes áreas que componen al sujeto colonizado, el cual fue cuestionado por sus producciones, como el concepto de tiempo circular; el concepto de dualidad que influye en su forma de concebir al otro como su semejante, lo que no indica que haya sido una sociedad ideal sin tensiones sociales; la comprensión del hombre como parte del todo y no sobre él, como lo propone Voltaire en su texto Cándido. De esta forma, se demuestra que los sujetos subalternizados tuvieron una epistemología propia, pero en el discurso oficial fueron despojados de su humanidad y sus producciones fueron omitidas para justificar su sometimiento y preservar los privilegios de los criollos y europeos. 


\section{Referencias bibliográficas}

Arouet, F. (1978). Antologia de Textos (Os Pensadores). São Paulo: Abril Cultura.

Akassi, Clément Animan. El Muntú en Manuel Zapata Olivella: Propuesta de una epistemología africana para descolonizar los imaginarios y los discursos latinoamericanos sobre las identidades.

Colombo, C. (1984). Diários da descoberta da América: as quatro viagens e o testamento. São Paulo: LPM.

Mercurio Peruano (1791-1795) (1960). Lima: Edición facsímil, Biblioteca Nacional del Perú.

Fanon, F. (1961). Los Condenados de la Tierra. México D.F.: FCE.

Fuentes, C. Révolution, annonciation. En Amado, JorgeL'Amérique Latine et la révolution française. Paris : Edit. : La Découverte, 1981.

Kant, E. (2013) Filosofía de la Historia. México D.F.: Fondo de Cultura Económica.

Lajo, J. QHÁPAQ Ñan: La Ruta Inka de la Sabiduría. Lima: Centro de Estudios Nueva Economía y Sociedad, 2005.

Mbembe, A. (2016) Critica de la Razón Negra. Barcelona: FAE. 
